\title{
Acute Scrotum: An Unusual Presentation of Non-gonococcal /Non Specific Urethritis,
Epididymitis and Orchitis (PART II) Non-gonococcal /Non Specific Urethritis,
Epididymitis and Orchitis (PART II)
}

\author{
Virendra N Sehgal*, Naresh Sehgal, Ruchi Sehgal, Jangid B. Lal
}

Department of Dermatology and Venereology, All India Institute of Medical Sciences and Research, New Delhi, India.

*Corresponding Author: Virendra N Sehgal, Department of Dermatology and Venereology, All India Institute of Medical Sciences and Research, New Delhi, India. Tel: 91-11-2767-0373;Fax: 91-11-2767-0373; E-mail: drsehgal@ndf.vsnl.net.in

\begin{abstract}
Acute scrotum, an unusual manifestation of non-gonococcal urethritis (NGU), epididymitis and orchitis, in a middle aged man is described with cardinal clinical features characterizing it as a syndrome. Investigations were corroborative to conform to non sexually transmitted disease. E. Coli, sensitive to levofloxacin, was recovered on culture, which showed an affirmative response to levofloxacin intravenous infusion, uriliser and urispas.
\end{abstract}

Keywords: Epididymis; Epididymitis; Orchitis; Urethritis; Infection; Syndrome

\section{Introduction}

Acute epididymo-orchitis ${ }^{[1]}$ perceived as a clinical syndrome $^{[2]}$, is a set of medical symptoms and signs that are correlated with each other, and often with a specific disease, characterized by pain, swelling and inflammation of the epididymis, with/without inflammation of the testes ${ }^{[3]}$. Local urethral extension is the most common route of infection, which may primarily be due to Gono-or non-gonococcal infection spreading from the urethra and /or from the bladder ${ }^{[4]}$. Although orchitis, an infection limited only to the testis is infrequent, may be an associated feature. There seemed to have been a steady decline in the prevalence of the condition in the recent past ${ }^{[5]}$. It is, therefore, considered, worthwhile to re-visit the entity to create an-awareness amongst the practitioners, about the condition the acute scrotum ${ }^{[6]}$.

\section{Case Report}

A 47-years-married man with single partner was admitted in the 'indoors' with spontaneous onset of severe pain and swelling confined to the left side of the scrotum. It was attended by sero-purulent, yellow-green discharge from the penis, burning, pain, urinary frequency and urgency (dysuria) and itching since March 3, 2015. He also had low grade fever. Ever-since the symptoms were on the increase without any perceptible relief. There was neither any history of extra-marital sex nor instrumentation/ catheterization.
Received date: September 12, 2015

Accepted date: September 23, 2015

Published date: September 28, 2015

Citation: Sehgal, V.N., et al. Acute Scrotum: An Unusual Presentation of Non-gonococcal /Non specific Urethritis, Epididymitis and Orchitis (PART II). (2015) Invest Dermatol Venereol Res 1(2): 22- 24.

Physical examination of the genitals was marked by erythema, edema and pigmentation of the skin of the scrotum apparent as well-circumscribed, oblong swelling. It was unilateral, and confined only to its left side (Figure 1,2) affecting the epididymis, vas deferens and testis. It was firmed and excruciatingly tender on palpation. The External urinary meatus was swollened, red and tender. Transillumination test for the hydrocele of the scrotum was negative.

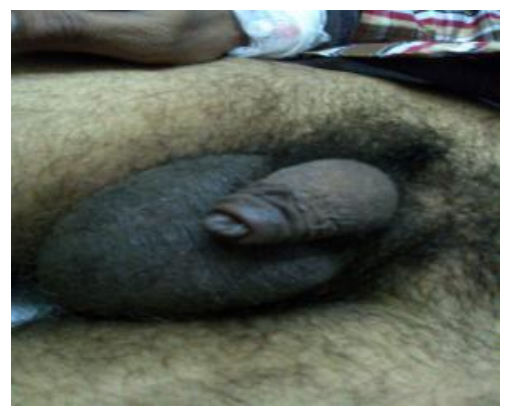

Figure 1: Acute Scrotum depicting erythema, edema and swelling.

Copy rights: (C2015 Sehgal, V.N. This is an Open access article distributed under the terms of Creative Commons Attribution 4.0 International License. 


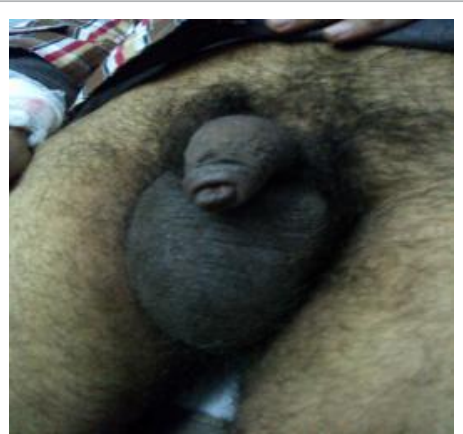

Figure 2: Acute Scrotum displaying erythema, edema and swelling of the scrotum skin confined to left side.

\section{Investigations}

Gram-stained smear prepared from urethral discharge from urethra was negative for gram-negative intra-and extra cellular diplococci, the Neisseria gonorrhoeae. Venereal disease research laboratory (VDRL) test was non-reactive. Human immunodeficiency virus (HIV) was negative.

\section{Culture and Sensitivity}

Escherichia Coli (E.Coli) was recovered from the urethral discharge / urine examination on culture on LB broth (Sigma-Aldrich). It was found to be sensitive to Co-trimoxazole, chloramphenicol, tetracycline, nitrofurantoin, Levofloxacin, azithromycin, amikacin, ceftizoxime, piperacillin/tazobactum and imipenem. Culture for Chlamydia trachomatis did not yield any growth on transport media.

\section{Ultrasonography ${ }^{[7]}$}

High resolution ultrasonography of the testis was performed to evaluate its status, using high frequency $11 \mathrm{Mhz}$ (MegaHertZ) linear probe; the left testis was normal in size, shape and echo-pattern. Loculated fluid was seen in tunica vaginalis with multiple thin septations. Left spermatic cord was thickened and heterogeneous. Increased vascularity was conspicuous (funiculitis). Left epididmymis size was enlarged, hypo-echoic with increased vascularity. No evidence of dilated veins was seen. Right testis was normal.

\section{Treatment}

Levofloxacin (Levotas) $0.5 \% \mathrm{~W} / \mathrm{v}$ in $500 \mathrm{mg} / 100 \mathrm{ml}$ infusion by slow intravenous (I.V) infusion, BDS, twice daily for ten injections spread over period of 5 days. This treatment was supplemented by oral administration of uriliser (Citric acid/ sodium citrate and potassium citrate) $5 \mathrm{ml}$ twice a day, and urispas (Flavoxate $\mathrm{HCl}$ ) in dosage of $200 \mathrm{mg}$ twice a day for 5 days. The response to the treatment was evident by slow regression of symptoms and signs during the follow- up period.

\section{Discussion}

Epididymo-orchitis is a well-recognized complication of NGU in men $^{[1-3]}$. It is a combination of epididymitis and orchitis. The former is an inflammation of the epididymis, along coiled tube in the testicles that helps store, and transport sperms, while the latter is an inflammation of the testis. It affects fewer than 1 in 100 men with NGU. Nevertheless, acute scrotum ${ }^{[6]}$ is one of the dreaded emergencies in practice ${ }^{[4]}$. The case under review documents its presenting clinical features, which are re- quired to be addressed expeditiously to alleviate patient's suffering. Furthermore, emergency evaluation of the patient presenting with acute scrotum using bedside Ultrasonography is imperative. Torsion of testis, hernia, hydrocele, varicocele and genital elephantiasis ${ }^{[8]}$ should be considered and excluded accordingly. It is, therefore, relevant to recall anatomy of the male genitals ${ }^{[9]}$ including the scrotum at this point in time through sketch (Figure 3 ) which should prove informative to comprehend the entity, complications and its ultimate management.

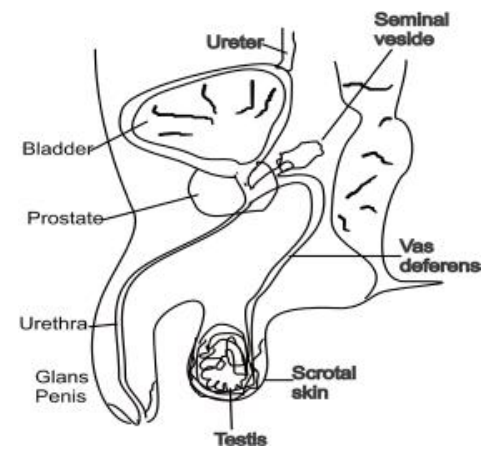

Figure 3: Anatomy of male genitals.

Infection of the urinary tract in men over 35 years is most often due to Gram-negative enteric organisms, E.Coli and Pseudomonas, specific risk factors being recent instrumentation or catheterization, ${ }^{[4,10,11]}$ whereas infection in men below 35 years of age is due to Chlamydia trachomatis and Neisseria gonorrhoeae, the sexually transmitted pathogens. There may be an overlap between the two, warranting recording of sexual history thoroughly. E. Coli was the offending organism in the present case. The management of such cases should take cognizance of guidelines Centers for disease control ${ }^{[12]}$.

Their periodic updates are invaluable, and should form a part component of treatment strategies, which take into account changing pattern of the disease from time to time. 


\section{References}

1. Weidner, W., Schiefer, H.G., Garbe, C. Acute nongonococcal epididymitis. Aetiological and therapeutic aspects. (1987) Drugs 34 (1Suppl): S111-S117.

2. Krieger, J.N. Epididymitis, orchitis and related conditions. (1984) Sex Transm Dis 11(3): 173-181.

3. Nicholson, A., Rait, G., Murray-Thomas. T., et al. Management of epididymo-orchitis in primary care: results from a large UK primary care database. (2010) Br J Gen Pract 60(579): e407-e422.

4. Walker, N.A., Challacombe, B. Managing epididymo-orchitis in general practice. (2013) Practitioner 257(1760): 21-25.

5. Horner, P., Blee, K., O’Mahony, C., et al. 2014 UK National Guideline on the Management of Non-gonococcal Urethritis. British Association for Sexual Health and HIV.

6. Blaivas, M., Sierzenski, P., Lambert, M. Emergency evaluation of patients presenting with acute scrotum using bedside ultrasonography. (2001) Acad Emerg Med 8(1): 90-93.

7. Pilatz, A., Wagenlehner, F., Bschleipfer, T., et al. Acute epididymitis in ultrasound: results of a prospective study with baseline and follow-up investigations in 134 patients. (2013) Eur J Radiol 82(12): e762-e768. 8. Gupta, S., Ajith, C., Kanwar, A.J., et al. Genital elephantiasis and sexually transmitted infections - revisited. (2006) Int J STD AIDS 17(3): 157-165.

9. Johnson, T.B., Davies, D.V., Davis, F. Grey's Anatomy 35 edn. (1973).

10. Bradshaw, C.S., Tabrizi, S.N., Read, T.R., et al. Etiologies of non-gonococcal urethritis: bacteria, viruses, and the association with orogenital exposure. (2006) J Infect Dis 193 (3): 336-345.

11. Kim, S.D., Kim, S.W., Yoon, B.I., et al. The Relationship between Clinical Symptoms and Urine Culture in Adult Patients with Acute Epididymitis. (2013) World J Mens Health 31(1): 53-57.

12. Workowski, K.A., Berman, S. Sexually Transmitted Diseases Treatment Guidelines. (2010) MMWR 59(RR-12): 1-110. 